Please do not remove this page

RMIT

UNIVERSITY

\title{
Wet etching techniques for the realisation of novel electrode structures on $X$ and Z-cut lithium niobate
}

Chong, Han; Mitchell, Arnan; Austin, Michael

https://researchrepository.rmit.edu.au/esploro/outputs/9921857672501341/filesAndLinks?institution=61RMIT_INST\&index=null

Chong, H., Mitchell, A., \& Austin, M. (2002). Wet etching techniques for the realisation of novel electrode structures on $X$ and Z-cut lithium niobate. Proceedings Conference on Optoelectronic and Microelectronic Materials and Devices, 2000. COMMAD 2000., 194-197.

https://researchrepository.rmit.edu.au/discovery/fulldisplay/alma9921857672501341/61RMIT_INST:Resea rchRepository

Repository homepage: https://researchrepository.rmit.edu.au

(c) 2000 IEEE. Personal use of this material is permitted. However, permission to reprint/republish this material for advertising or promotional purposes or for creating new collective works for resale or redistribution to servers or lists, or to reuse any copyrighted component of this work in other works must be obtained from the IEEE.

Downloaded On 2023/04/26 21:49:22 +1000 


\title{
Wet Etching Techniques for the Realisation of Novel Electrode Structures on $X$ and Z-cut Lithium Niobate
}

\author{
H. W. Chong", A. Mitchell" and M. W. Austin ${ }^{*}$ \\ Australian Photonics CRC, RMIT University, Australia
}

\begin{abstract}
Lithium niobate $\left(\mathrm{LiNbO}_{3}\right)$ is a popular material for the implementation of many photonic devices, but most often for broadband electro-optic (EO) modulators. Effective modulators may be realised through careful design of the RF electrodes. The most successful electrode designs incorporate some form of surface machining and thus in order to explore novel practical electrode structures, it has been necessary to develop means of etching the $\mathrm{LiNbO}_{3}$ surface precisely. In this paper, we present the etching of $\mathrm{LiNbO}_{3}$ using a proton exchange (PE) wet etching method including a detailed comparison of the etch properties of $\mathrm{X}$ and $\mathrm{Z}$-cut $\mathrm{LiNbO}_{3}$.
\end{abstract}

\section{A. Introduction}

Recently, increasingly efficient and highly broadband optical modulators in lithium niobate $\left(\mathrm{LiNbO}_{3}\right)$ have been developed [1]. Key to the performance of these devices are the properties of the traveling wave electrode structure that carries the RF signal to be transferred onto the optical carrier. The attenuation must be as low as possible, and the microwave and optical effective indices must be carefully matched. Many novel concepts for index matching in these electrode structures have been proposed. Several of the more successful demonstrations [1] utilise etched trenches to reduce the microwave index by including air in the trenches between the electrodes to lessen the effect of $\mathrm{LiNbO}_{3}$ 's high dielectric constant and thus the achieve velocity matching between the optical carrier and the electrical signal.

As a first step in the pursuit of such optimal electrode structures, this paper investigates and characterises the wet etching rate for $\mathrm{X}$-cut and $\mathrm{Z}$-cut $\mathrm{LiNbO}_{3}$. The process is based on proton exchange (PE) in benzoic acid $\left(\mathrm{C}_{6} \mathrm{H}_{5} \mathrm{COOH}\right)$ followed by etching of the exchanged material in a mixture of $\mathrm{HF}$ and $\mathrm{HNO}_{3}$ [2]. A detailed analysis of the etch-rate for several different etching environments for both material cuts and with both positive and negative faces is presented. Etch depths of several microns are achievable in all cases with practical sidewall roughness and incline. No preference for etching of the positive or negative faces is found for X-cut material, while for Z-cut, although the two faces behave differently, practical etching is possible for each. An investigation of accelerating the procedure has resulted in $18 \mu \mathrm{m}$ ridges being achieved within 3 hours of etching on the PE $+Z$-cut face.

\section{B. Theory of Etching}

The use of chemically etched $\mathrm{LiNbO}_{3}$ has been reported previously $[2,3,6]$. To understand and interpret the nature of the etching of $\mathrm{LiNbO}_{3}$, it is useful to examine the chemistry of the PE wet etch process. $\mathrm{PE}$ involves indiffusion of protons $\left(\mathrm{H}^{+}\right)$from a proton source into and out-diffusion of interstitial ions $\left(\mathrm{Li}^{+}\right)$from the crystal lattice. Theoretically, this is a one to one proton replacement process. We used benzoic acid as our proton source. The process can be summarised by the following chemistry equilibrium condition [4]:

$$
\mathrm{LiNbO}_{3}+\mathrm{C}_{6} \mathrm{H}_{5} \mathrm{COOH} \rightarrow \mathrm{Li}_{1-\mathrm{x}} \mathrm{H}_{\mathrm{x}} \mathrm{NbO}_{3}+\left(\mathrm{C}_{6} \mathrm{H}_{5} \mathrm{COOLi}\right)_{\mathrm{X}}
$$

\footnotetext{
* arnan.mitchell2rmit.edu.au; phone +6139925 2457; fax +61 39662 1921; Australian Photonics Cooperative Centre, SECSE, RMIT University, GPO BOX 2476V, Melbourne, 3001, Australia.
} 
The $\mathrm{PE} \mathrm{LiNbO}_{3}$ is less resilient than un-exchanged $\mathrm{LiNbO}_{3}$ and thus it may be preferentially etched using $\mathrm{HF}$ acid diluted with $\mathrm{HNO}_{3}$. Under the correct conditions, $\mathrm{PE}$ of $+\mathrm{Z}$ oriented $\mathrm{LiNbO}_{3}$ leads to ferroelectric domain inversion, resulting in $-\mathrm{Z}$ orientation. The contrast between the HF etch rates of $+Z$ and $-Z$ domains is particularly strong making this process an excellent technique for patterning of regions to be etched.

\section{Proton Exchange and Wet Etching Method}

Patterned masks in both $\mathrm{Cr}(3000 \AA)$ and Ti $(1000 \AA)$ were deposited on samples of four orientations $(+Z,+X,-Z$ and $-X)$ using e-beam evaporation and lift-off photolithography. Eight samples in all were then subjected to the same PE process.

To perform the PE, the samples were mounted onto a Teflon holder and immersed in a Pyrex beaker of molten benzoic acid at $240^{\circ} \mathrm{C}$ for 6 hours. An airtight Teflon cover was used to minimise the effect of differential evaporation. In order to stabilise and maintain the bath temperature within $\pm 0.1^{\circ} \mathrm{C}$, the entire unit was immersed in a Silicone oil bath. A magnetic stirrer was used to ensure a fresh proton source flowing continuously to the sample. After PE, the whole unit was allowed to cool to $120^{\circ} \mathrm{C}$ and the sample was removed and immersed into preheated DI water and allowed to cool further to room temperature (RT). The recrystallised acid on the sample was removed using heated chloroform and then DI water. The PE masks survived the process and were retained as a mask for the wet etch procedure.

The unmasked portions of the sample were then etched by immersion in a mixture of two parts $\mathrm{HNO}_{3}$ and one part $\mathrm{HF}$ for several hours. The wet etch was conducted at room temperature and also at an elevated temperature. The room temperature etch was sustained for about 7 hours. The elevated temperature was conducted for only 3 hours, starting at a temperature of $70^{\circ} \mathrm{C}$ for the first hour, reducing to $40^{\circ} \mathrm{C}$ for the second hour and then $25^{\circ} \mathrm{C}$ for the third hour. This was done to allow rapid coarse etching initially and to finish with slower etching rate with a polishing effect. Ultrasonic agitation was used during all etching procedures to prevent precipitates depositing on the surface and to ensure a smooth uniform finish. After etching, the PE mask was removed and the sample was cleaned with isopropyl alcohol and running DI water.

\section{Results and discussion}

The surface morphology of the etched samples was examined using a stylus type profilometer and scanning electron microscope (SEM). Figures 1 a)-d) show the etched profiles of Z-cut material using a $\mathrm{Cr}$ PE mask and the elevated temperature etching scheme. Figure 1a) shows the cross section of an $18 \mu \mathrm{m}$ thick ridge on $+Z$-cut surface. This was achieved with just three hours etching and is among the deepest etch depths reported for the $\mathrm{PE} / 1 \mathrm{HF}: 2 \mathrm{HNO}_{3}$ etch technique [2].

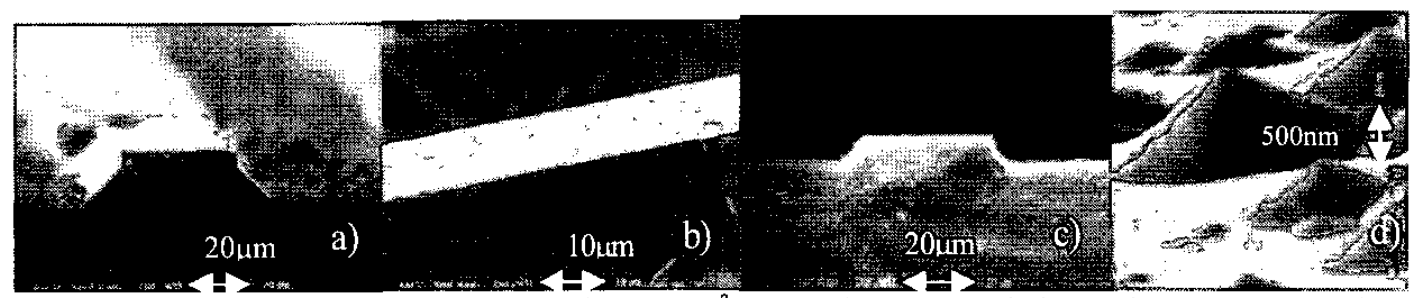

Fig. 1: Ridges etched on $\mathrm{Z}$-cut $\mathrm{LiNbO}_{3}$ using $3000 \AA \mathrm{Cr}$ mask for $\mathrm{PE}$ and elevated temperature etching in $\mathrm{HF}$, a) cross-section $18 \mu \mathrm{m}$ ridge on $+Z$, b) smooth sidewalls of $18 \mu \mathrm{m}$ ridge on $+Z$, c) $5.5 \mu \mathrm{m}$ ridge on $-Z, d$ ) sparse hillocks on-Z. 
Figure 1b) shows the sidewalls of the same ridge. A smooth ridge surface is evident, however dense hillocks remain on the etched surface. Figure 1c) presents the cross-section of a $5.5 \mu \mathrm{m}$ ridge on $-\mathrm{Z}$ oriented $\mathrm{LiNbO}_{3}$ using similar etch conditions as for the $+\mathrm{Z}$ orientation. The etch rate is clearly slower for this orientation and the sidewalls are evidently less abrupt. Pyramidal hillocks revealed on the etched surfaces are presented in Figure 1 d), however no etched pits, as reported in [5], were observed.

Figures 2 a) \& b) and c) \& d) show the etched profiles of X-cut material using $1000 \AA$ $\mathrm{Ti}$ and $3000 \AA \mathrm{Cr} \mathrm{PE}$ masks respectively and then room temperature etching. Figures 2 a) and b) show a top and an oblique view of the sidewall of $4 \mu \mathrm{m}$ thick ridges on $+X$ and $-X$ faces respectively. This $4 \mu \mathrm{m}$ ridge required 20 hours of etching. The ridges are well defined and the surface is quite smooth. In contrast, samples that underwent the same PE and etching process using a $\mathrm{Cr} P E$ mask are presented in Figures $2 \mathrm{c}$ ) and d) for the $+\mathrm{X}$ and $-\mathrm{X}$ faces respectively. The $\mathrm{Cr}$ mask has not been removed at this stage to allow identification of the masked region. No distinguishable etched profile and a significant undercut and rough exposed surface is clearly visible in each case.

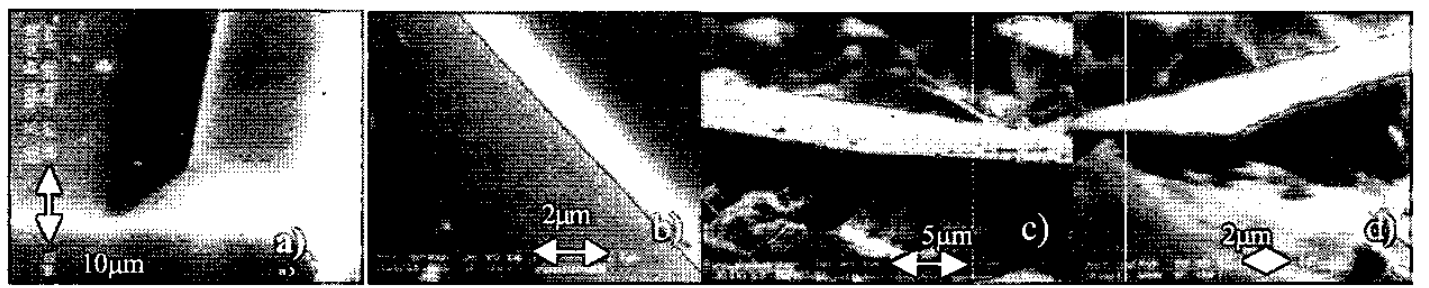

Fig. 2: Ridges etched on $X$ cut using room temperature etching in HF. a) $4 \mu \mathrm{m}$ ridge on $+X$ using 1000 $\AA$ Ti mask, b) $4 \mu \mathrm{m}$ ridge on -X using $1000 \AA$ Ti mask, c) failed etching on $+\mathrm{X}$ using $3000 \AA \mathrm{Cr}$ mask (still present), d) failed etching on -X using $3000 \AA \mathrm{Cr}$ mask (still present).

Also, X-cut material exhibits no difference in etch-rate for positive and negative faces, which is not often emphasised in other studies [6]. The formation of ridges on the X-cut material is due only to the preferential etching of disrupted PE region and is unlikely to be assisted by domain inversion as is the case with $\mathrm{Z}$-cut material. Also, $\mathrm{X}$-cut $\mathrm{LiNbO}_{3}$ is found to be more susceptible to surface damage due to strain induced by high exchange temperature, long exchange time and/or temperature shock than Z-cut material, precluding the use of elevated temperature etching to accelerate the etching process. Thus, the achievable depth and etch rate in $\mathrm{X}$-cut material is significantly less than that achievable with Z-cut.

The $-\mathrm{Z}$ oriented $\mathrm{LiNbO}_{3}$ is more difficult to domain invert than the $+\mathrm{Z}$ orientation for reasons analogous to $-\mathrm{Z}$ face in $\mathrm{LiTaO}_{3}$ [8]. It is thus likely then that the preferential etching of the exposed material is due mostly to the disruption of the crystal caused by the PE process. This is supported by the gradual sidewall angle evident in Figure 1c). The etching was faster and deeper than that of both X-cut types. This is due to the application of elevated temperature etching. The $+Z$ orientation offers the fastest and deepest etching. Strong preferential etching is observed as evidenced by the very abrupt sidewalls at the top of the ridge in Figure 1a). This is likely primarily due to domain inversion of the $+Z$ crystal to $-Z$. The etching then continues with an angled wall. It is proposed that this junction occurs at the diffusion depth of the $\mathrm{H}+$ ions in the PE procedure. Crystal disruption, due to the PE process, along with elevated temperature further contributes to this very fast and deep etching. Previously reported results [2-7] present further discussion of the differences between PE/wet etch characteristics for various forms of $\mathrm{LiNbO}_{3}$. 
To examine the etch rates of the various $\mathrm{LiNbO}_{3}$ orientations in detail, samples of $+\mathrm{Z},-\mathrm{Z}$ and $+\mathrm{X}$ cut $\mathrm{LiNbO}_{3}$ were $\mathrm{PE}$ using $1000 \AA \mathrm{Ti}$ mask and etched at room temperature. The etching was interupted every 15 minutes and the sample removed and cleaned in DI water and then profiled. The resulting ridge height as a function of etch-duration is presented in Figure 3. Etching for the two Z-cut samples begins rapidly, but slows after a few microns of etching. It is proposed that this slowing occurs as the PE domain boundary is reached. In contrast, the X-cut sample etches more slowly, but the rate reduces steadily with time rolling off slowly towards the end of the process. It is proposed that the depletion of the etchant is responsible for this roll off. The deeper etching in $+Z$ material can be attributed to the strong differential etching condition in the selectively $\mathrm{PE}$ and domain inverted surface.

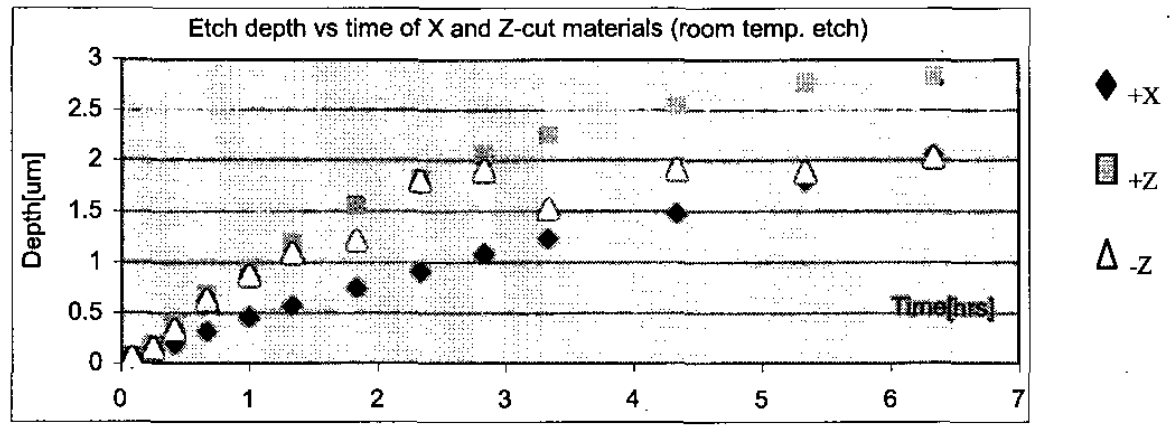

\section{E. Conclusion}

Fig. 3: Etch rates for $\mathrm{X}$ and $\mathrm{Z}$-cut materials

We have successfully fabricated practical ridge structures in both positive and negative faces of $\mathrm{X}$ and $\mathrm{Z}$-cut $\mathrm{LiNbO}_{3}$ material. Different etch characteristics and surface morphologies have been identified and explanations for these observations have been proposed. Very fast deep etching was achieved for the $+\mathrm{Z}$ orientation of $\mathrm{LiNbO}_{3}$, with an etch depth of $18 \mu \mathrm{m}$. A quantitative comparison of the etch rates for $\mathrm{X}$ and $\mathrm{Z}$-cut $\mathrm{LiNbO}_{3}$ has also been presented. The next step will be to examine the compatibility of this etch process with $\mathrm{Ti}$ indiffusion and also to investigate its impact on the electro-optic effect. This will then allow us to utilise these etched ridges in the realisation of optimised index matched electrodes on $\mathrm{X}$ and Z-cut material for high-speed broadband modulators.

\section{Acknowledgements}

We thank RMIT Department of Applied Physics for using their scanning electron microscope (SEM) facility; and Ms M.S. Chan for valuable discussion and encouragement.

\section{References}

[1] O.Mitomi, K.Naguchi and H.Miyazawa, IEEE T. Microw. Theory Tech. 43 (1995) 2203.

[2] F.Laurell, J.Webjörn, G.Arvidsson and J.Holmberg, J. Lightw. Tech. 10 (1992) 1606.

[3] R. S. Cheng, T.J. Wang and W.S. Wang, J. Lightw. Tech. 15, (1997) 1880.

[4] S.T. Vohra and A.R. Mickelson, J. Appl. Phys. 66 (1989) 5161.

[5] N. Ohnishi and T. Iizuka, J. Appl. Phys. 46, (1975) 1063.

[6] S.J. Chang, C.L. Tsai, Y.B. Lin, J.F: Liu and W.S. Wang, J. Lightw. Tech. 17 (1999) 843.

[7] J.Webjörn, J. Lightw. Tech. 11 (1993) 589.

[8] K.Nakamura, M.Hosoya and A.Tourlog, J. Appl. Phys. 73 (1993) 1390. 